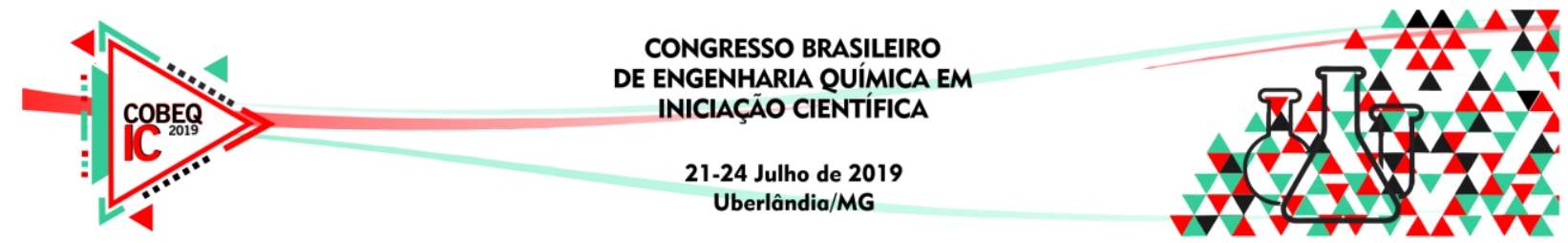

\title{
USO DE SECADOR ROTATÓRIO COM RECHEIO DE INERTES NA DESIDRATAÇÃO DO CAMU-CAMU (Myrciaria dubia)
}

\author{
T. C. FONSECA ${ }^{1}$, T. C. SILVA ${ }^{1}$, N. C. SILVA ${ }^{1}$, C. R. DUARTE ${ }^{1}$ e M. A. S. BARROZO ${ }^{1}$ \\ ${ }^{1}$ Universidade Federal de Uberlândia, Faculdade de Engenharia Química \\ E-mail para contato: thabata.carmo.fonseca@hotmail.com
}

\begin{abstract}
RESUMO - O camu-camu (Myrciaria dubia) é um fruto tropical nativo da região Amazônica, que têm despertado interesse pelo seu elevado conteúdo de vitamina $\mathrm{C}$ e de compostos antioxidantes. Porém, o mesmo também é caracterizado por apresentar alto teor de umidade, sendo necessária a aplicação de técnicas de desidratação para seu aproveitamento. Dentre as metodologias existentes, o secador rotatório com recheio de inertes tem tido grande relevância uma vez que o equipamento se destaca pela possibilidade de secar materiais pastosos e por possuir um produto pós-secagem pronto para comercialização. Para definição da melhor condição experimental de secagem da polpa, almejando-se a obtenção de um produto com pouca umidade, baixa atividade de água e de um processo com bom rendimento, foram explorados os efeitos de diferentes variáveis de processo como concentrações de agente carreador (maltodextrina), da temperatura do ar, do fator de enchimento e da velocidade de rotação. Os resultados obtidos indicaram a eficiência desse método para um possível aproveitamento do camu-camu desde que a desidratação seja realizada em condições adequadas de suas variáveis.
\end{abstract}

\section{INTRODUÇÃO}

O fruto do camu-camu (Myrciaria dubia) originário da região amazônica tem se destacado por despertar o interesse de indústrias farmacêuticas internacionais devido seus elevados teores de antioxidantes, em especial a vitamina C. Contudo, essa alta concentração de compostos antioxidantes acarreta um sabor ácido à fruta inibindo o consumo in natura (Rodrigues et al., 2004). Juntamente a essa acidez característica, a polpa de camu-camu também tem elevada quantidade de água, que torna o fruto altamente perecível (Fujita et al., 2013) sendo necessário portanto a aplicação de um método para a desidratação do material.

Dentre as variadas técnicas de desidratação, tem-se destacado o secador rotatório que possui como vantagens a eficiência na remoção da umidade e promoção de uma secagem mais homogênea devido ao seu alto grau de mistura de partículas (Krokida et al., 2002). Como a biomassa do camu-camu é pastosa, o uso de inertes dentro do secador rotatório se torna bastante efetivo, uma vez que os mesmos maximizam a troca térmica e evitam perdas do material nas paredes e outras estruturas do secador (Freitas, 2017).

Diante de todos estes fatos, o objetivo deste trabalho foi realizar a desidratação do camu-camu utilizando um secador rotatório com recheio de inertes, analisando o impacto da 


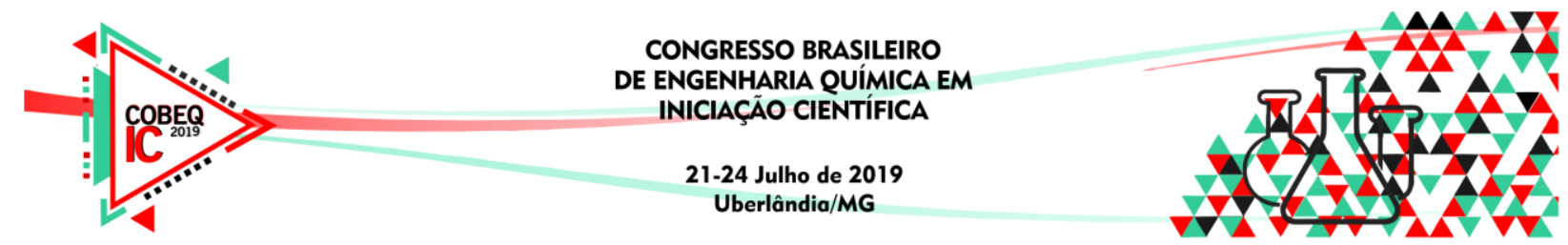

variação das condições de operação sobre o processo de remoção de umidade e do rendimento de secagem.

\section{MATERIAL E MÉTODOS}

O camu-camu utilizado foi fornecido por um sítio localizado em Ibiá-MG. Preparou-se a polpa dos frutos adicionando água destilada na proporção mássica 3:4 (3 g de água para cada $4 \mathrm{~g}$ de fruto). A polpa foi armazenada em copos plásticos, envoltos em polietileno e papel alumínio, sendo mantidos em freezer à $-18^{\circ} \mathrm{C}$, até o momento da realização dos experimentos.

A unidade experimental utilizada, representada na Figura 1, consistia em um soprador, conectado à um sistema de aquecimento e um variador de voltagem para ajustar a temperatura do ar. O tambor foi conectado a um sistema de rotação composto por um motor e inversor de frequência para controle da velocidade de rotação. Um ciclone Stairmand de diâmetro $10 \mathrm{~cm}$ e com um frasco acoplado em seu underflow foi utilizado para coleta do material desidratado. $\mathrm{O}$ camu-camu in natura foi alimentado por um sistema composto por um tanque de armazenamento, bomba peristáltica e controlador de velocidade. $\mathrm{O}$ tambor usado nesse trabalho foi feito de aço inox, com diâmetro interno de $12 \mathrm{~cm}$ e comprimento de $36 \mathrm{~cm}$. Os inertes utilizados foram esferas de porcelana, com diâmetro de 1,9 cm e densidade de 2,32 $\mathrm{g} / \mathrm{cm}^{3}$.

Figura 1- Figura esquemática do secador rotatório com recheio de inertes.

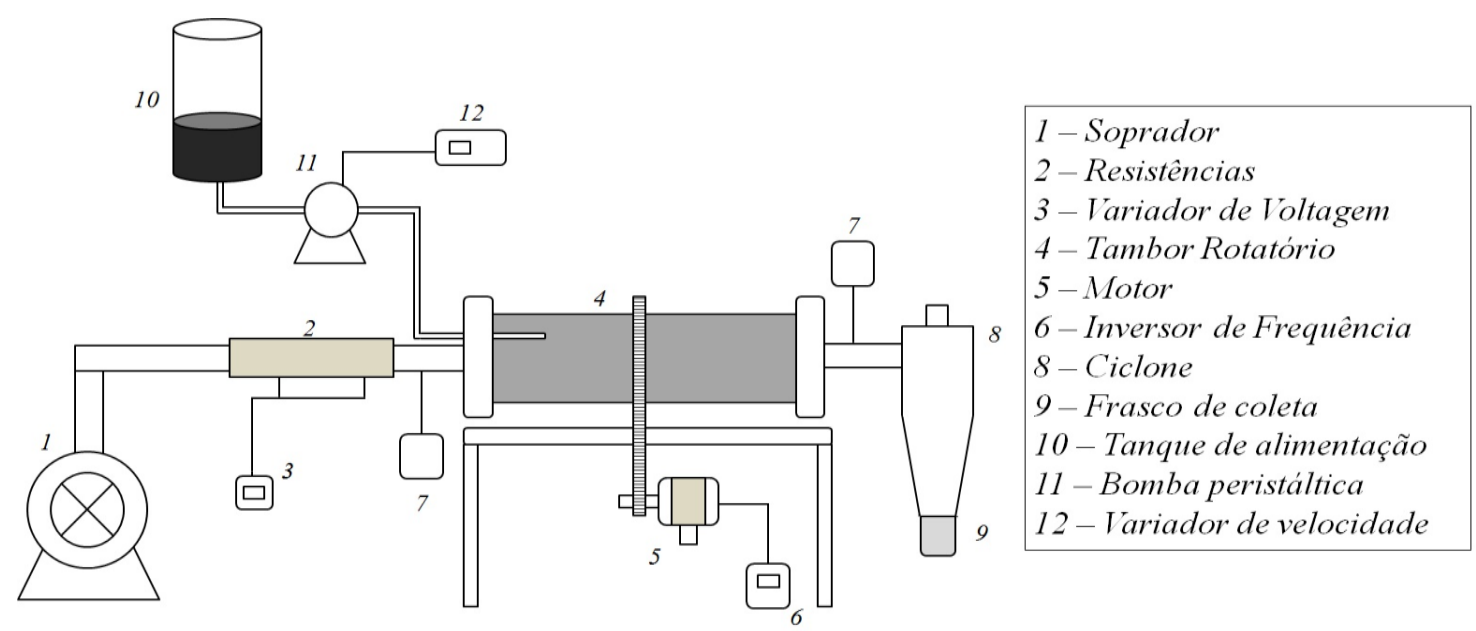

Utilizou-se cerca de $100 \mathrm{~g}$ de polpa de camu-camu em cada experimento, alimentadas na forma de ciclos intermitentes. Analisou-se os impactos das variáveis temperatura, enchimento e rotação no processo de secagem, assim como expresso na Tabela 1. Além dessas variáveis, verificou-se também os efeitos de diferentes concentrações de maltodextrina na polpa durante a secagem, realizando-se uma série de experimentos em concentrações distintas desse agente carreador. Após descongelada, a polpa era misturada com a maltodextrina (Loremalt, DE11). A concentração era calculada da seguinte forma: para 10\% de maltodextrina, adicionava-se $10 \mathrm{~g}$ do agente carreador à $100 \mathrm{~g}$ de polpa, e assim, para as demais concentrações. 


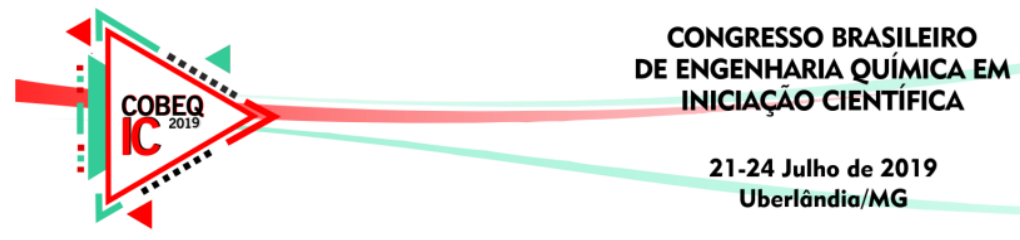

Tabela 1- Condições experimentais na desidratação do camu-camu.

\begin{tabular}{|c|c|c|c|c|}
\hline Experimento & $\begin{array}{c}\text { Temperatura } \\
\left({ }^{\circ} \mathrm{C}\right)\end{array}$ & $\begin{array}{c}\text { Maltodextrina } \\
(\%)\end{array}$ & $\begin{array}{c}\text { Enchimento } \\
(\%)\end{array}$ & $\begin{array}{c}\text { Rotação } \\
(\text { RPM })\end{array}$ \\
\hline 1 & 70 & 0 & 28 & 65 \\
\hline 2 & 70 & 10 & 28 & 65 \\
\hline 3 & 70 & 15 & 28 & 65 \\
\hline 4 & 70 & 20 & 28 & 65 \\
\hline 5 & 70 & 30 & 28 & 65 \\
\hline 6 & 90 & 15 & 28 & 65 \\
\hline 7 & 110 & 15 & 28 & 65 \\
\hline 8 & 90 & 15 & 21 & 65 \\
\hline 9 & 90 & 15 & 35 & 65 \\
\hline 10 & 90 & 15 & 28 & 55 \\
\hline 11 & 90 & 15 & 28 & 75 \\
\hline
\end{tabular}

As análises realizadas, tanto no material in natura quanto após a desidratação foram: umidade, determinada através do método da estufa submetendo as amostras à $105 \pm 3^{\circ} \mathrm{C}$ por 24 horas (AOAC, 1995); a atividade de água $\left(\mathrm{a}_{\mathrm{w}}\right)$ através do equipamento Lab-Swift AW, Novasina; a análise de Temperatura de Transição Vítrea (Tg), na qual as amostras foram submetidas à análise por calorimetria diferencial de varredura (DSC) para determinação da Tg utilizando-se um equipamento de DSC da TA Instruments (New Castle - EUA), Modelo Q20 V24.4 Build 116. O rendimento de secagem foi obtido através da relação entre massa de pó produzido (base seca) por massa de polpa alimentada (base seca), sendo expresso em porcentagem $(\%)$.

\section{RESULTADOS E DISCUSSÃO}

\subsection{Umidade final (UF) e atividade de água $\left(a_{w}\right)$}

A umidade final e a atividade de água da polpa desidratada de cada experimento e também in natura estão expressas na Tabela 2.

Tabela 2- Umidade final e atividade de água da polpa de camu-camu desidratada e in natura.

\begin{tabular}{|c|c|c|c|c|c|c|}
\hline Experimento & $\begin{array}{c}\text { Temperatura } \\
\left({ }^{\circ} \mathrm{C}\right)\end{array}$ & $\begin{array}{c}\text { Maltodextrina } \\
(\%)\end{array}$ & $\begin{array}{c}\text { Enchimento } \\
(\%)\end{array}$ & $\begin{array}{c}\text { Rotação } \\
(\mathrm{RPM})\end{array}$ & $\begin{array}{c}\text { Umidade } \\
(\%)\end{array}$ & $\begin{array}{c}\text { Atividade } \\
\text { água } \\
\left(\mathrm{A}_{\mathrm{w}}\right)\end{array}$ \\
\hline 1 & 70 & 0 & 28 & 65 & 10,82 & 0,369 \\
\hline 2 & 70 & 10 & 28 & 65 & 6,20 & 0,327 \\
\hline 3 & 70 & 15 & 28 & 65 & 5,40 & 0,293 \\
\hline 4 & 70 & 20 & 28 & 65 & 4,59 & 0,276 \\
\hline 5 & 70 & 30 & 28 & 65 & 3,66 & 0,240 \\
\hline 6 & 90 & 15 & 28 & 65 & 4,44 & 0,229 \\
\hline 7 & 110 & 15 & 28 & 65 & 3,56 & 0,251 \\
\hline 8 & 90 & 15 & 21 & 65 & 4,56 & 0,234 \\
\hline
\end{tabular}




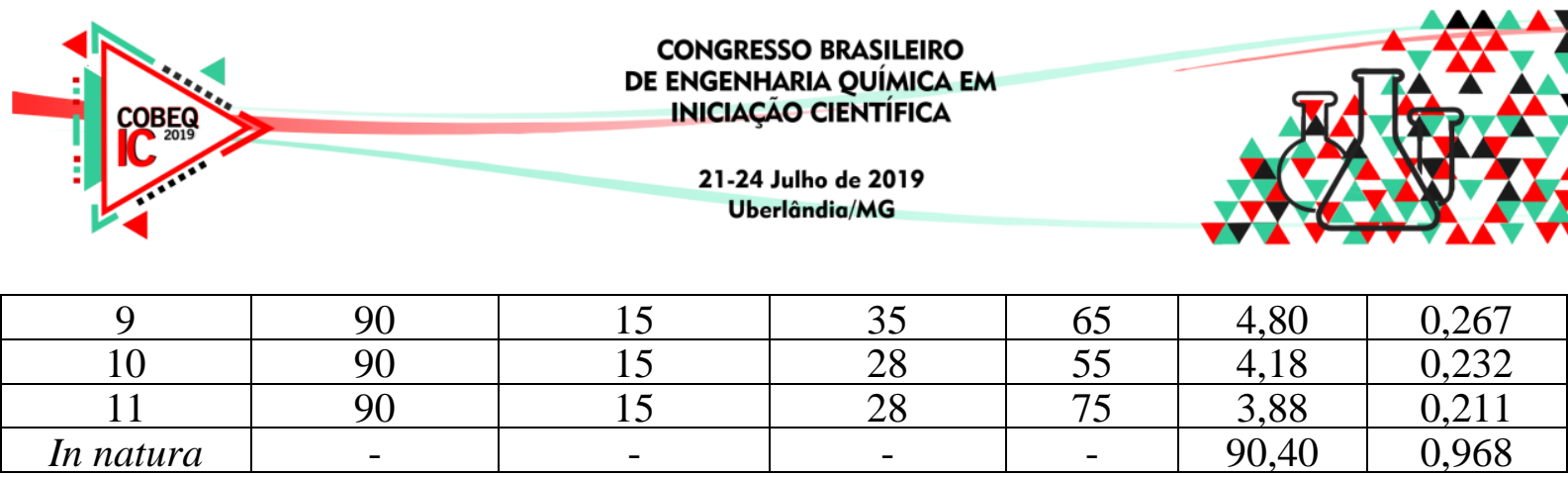

Através da análise dos resultados mostrados na tabela 2, observou-se que em todos os experimentos, a polpa do camu-camu desidratada atingiu valores satisfatórios de atividade de água $\left(a_{w}\right.$ inferiores a 0,6$)$ e umidade final, visto que em algumas literaturas a faixa de umidade desejável para armazenamento de um alimento desidratado são inferiores a 10\% (Angel et al., 2009). O menor valor foi obtido quando as condições operacionais estavam em maior temperatura e em valores intermediários de fator de enchimento, rotação e concentração de maltodextrina. Quando se alterou o valor de uma variável e manteve-se todas as outras constantes, foram observados comportamentos distintos: variando-se a rotação, o menor valor de umidade foi obtido para o maior valor desta variável; o mesmo ocorreu quando variou-se a concentração de maltodextrina e a temperatura, sendo que o aumento destas variáveis impactaram positivamente na remoção de umidade.

Tal impacto é justificado pela cinética de remoção de umidade ser superior com temperatura de ar de secagem maior, bem como o contato gás-sólido ser mais eficiente utilizando maior rotação do tambor de secagem (Limaverde Jr., 2000). Além disso, a adição de maltodextrina aumenta o conteúdo de sólidos totais da polpa, reduzindo a quantidade de água a ser evaporada, o que acarreta a diminuição da umidade dos pós produzidos. No entanto, ao modificar os valores de fator de enchimento notou-se um comportamento diferente, sendo que o menor valor de umidade é observado para um fator de enchimento intermediário.

\subsection{Análise do rendimento $(\%)$}

Os rendimentos obtidos para o camu-camu desidratado com diferentes concentrações de maltodextrina estão expostos na Tabela 3 abaixo.

Tabela 3- Rendimentos obtidos para diferentes concentrações de maltodextrina.

\begin{tabular}{|c|c|c|c|c|c|c|}
\hline Experimento & $\begin{array}{c}\text { Temperatura } \\
\left({ }^{\circ} \mathrm{C}\right)\end{array}$ & $\begin{array}{c}\text { Maltodextrina } \\
(\%)\end{array}$ & $\begin{array}{c}\text { Enchimento } \\
(\%)\end{array}$ & $\begin{array}{c}\text { Rotação } \\
(\mathrm{RPM})\end{array}$ & $\begin{array}{c}\mathrm{Tg} \\
\left({ }^{\circ} \mathrm{C}\right)\end{array}$ & $\begin{array}{c}\text { Rendimento } \\
(\%)\end{array}$ \\
\hline 1 & 70 & 0 & 28 & 65 & $-4,27$ & 38,23 \\
\hline 2 & 70 & 10 & 28 & 65 & 36,05 & 49,85 \\
\hline 3 & 70 & 15 & 28 & 65 & 41,43 & 52,32 \\
\hline 4 & 70 & 20 & 28 & 65 & 48,79 & 52,08 \\
\hline 5 & 70 & 30 & 28 & 65 & 43,86 & 46,73 \\
\hline
\end{tabular}

Através da Tabela 3 observamos que a justificativa de se utilizar a maltodextrina como agente carreador está demonstrada pelo rendimento do Experimento 1, no qual foi obtido um produto com aspecto pegajoso, com partículas aglomeradas e com grande aderência às paredes internas do secador rotatório e ao material inerte, gerando um baixo rendimento. Com 


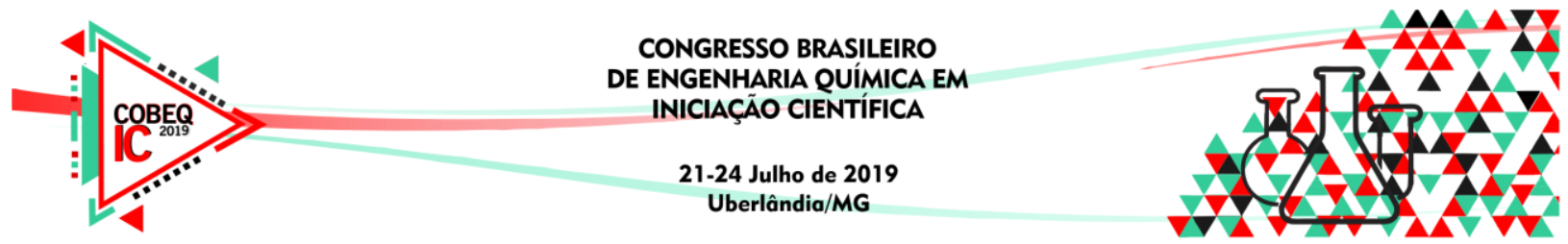

a adição do agente carreador, ocorreu um aumento da temperatura de transição vítrea do material, estabelecendo uma maior estabilidade à secagem do material.

Visando um maior rendimento, através do aumento da temperatura de transição vítrea, foram utilizadas concentrações de maltodextrina de 10,15, 20 e 30\% para experimentos com temperatura, fator de enchimento e rotação constantes. A partir dos dados experimentais notou-se um aumento no valor do rendimento até uma concentração intermediária do agente carreador e, a partir deste ponto o rendimento decaiu. A partir disso, encontrou-se um ponto ótimo para a concentração de maltodextrina, sendo este o valor de $15 \%$.

A partir dessa concentração de maltodextrina, variou-se a temperatura, mantendo a velocidade de rotação e o fator de enchimento constantes (Tabela 4). Verificou-se que o rendimento aumentou com o acréscimo da temperatura, entretanto, a diferença entre os experimentos 6 e $7\left(90^{\circ} \mathrm{C}\right.$ e $\left.110^{\circ} \mathrm{C}\right)$ foi mínima, sendo preferencial neste caso a escolha do experimento de menor temperatura visando um menor gasto energético do processo.

Tabela 4- Rendimentos obtidos para diferentes temperaturas.

\begin{tabular}{|c|c|c|c|c|c|}
\hline Experimento & $\begin{array}{c}\text { Temperatura } \\
\left({ }^{\circ} \mathrm{C}\right)\end{array}$ & $\begin{array}{c}\text { Maltodextrina } \\
(\%)\end{array}$ & $\begin{array}{c}\text { Enchimento } \\
(\%)\end{array}$ & $\begin{array}{c}\text { Rotação } \\
(\mathrm{RPM})\end{array}$ & $\begin{array}{c}\text { Rendimento } \\
(\%)\end{array}$ \\
\hline 3 & 70 & 15 & 28 & 65 & 52,32 \\
\hline 6 & 90 & 15 & 28 & 65 & 55,33 \\
\hline 7 & 110 & 15 & 28 & 65 & 55,36 \\
\hline
\end{tabular}

Definidos os melhores valores de concentração de maltodextrina e temperatura, avaliou-se o efeito da rotação e do enchimento no rendimento, cujos resultados são apresentados na Tabela 5.

Tabela 5- Rendimentos obtidos para diferentes enchimentos e rotações.

\begin{tabular}{|c|c|c|c|c|c|}
\hline Experimento & $\begin{array}{c}\text { Temperatura } \\
\left({ }^{\circ} \mathrm{C}\right)\end{array}$ & $\begin{array}{c}\text { Maltodextrina } \\
(\%)\end{array}$ & $\begin{array}{c}\text { Enchimento } \\
(\%)\end{array}$ & $\begin{array}{c}\text { Rotação } \\
(\mathrm{RPM})\end{array}$ & $\begin{array}{c}\text { Rendimento } \\
(\%)\end{array}$ \\
\hline 6 & 90 & 15 & 28 & 65 & 55,33 \\
\hline 8 & 90 & 15 & 21 & 65 & 50,82 \\
\hline 9 & 90 & 15 & 35 & 65 & 53,40 \\
\hline 10 & 90 & 15 & 28 & 55 & 53,86 \\
\hline 11 & 90 & 15 & 28 & 75 & 49,51 \\
\hline
\end{tabular}

A partir da tabela 5 notou-se que à medida que o fator de enchimento aumentou, o rendimento também elevou-se, muito provavelmente por ampliar a superfície de contato entre o ar de secagem e o material a ser seco. Comparando-se os experimentos 6 e 9, que apresentam diferença apenas na variável enchimento, verificou-se que a diferença entre os rendimentos foi pequena, então optou-se por utilizar um valor intermediário de fator de enchimento (28\%). Entretanto quando houve um incremento na rotação, o comportamento foi semelhante ao obtido para concentração de maltodextrina, ou seja, o rendimento decaiu. A partir disso, encontrou-se um ponto ótimo para a rotação também no experimento 6 (65 RPM), no qual o valor de rendimento obtido foi maior que nos experimentos 10 e 11. 


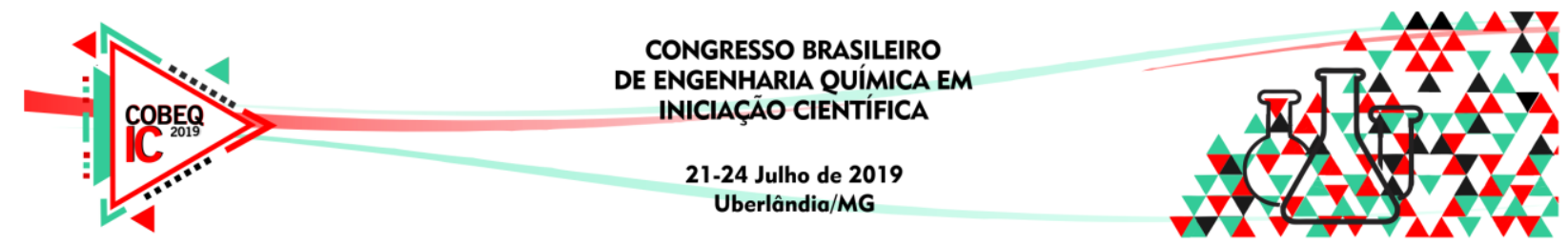

Portanto, definiu-se o Experimento 6, no qual utilizou-se $15 \%$ de concentração de maltodextrina, temperatura do ar de secagem de $90^{\circ} \mathrm{C}$, fator de enchimento de $28 \%$ e rotação igual a 65 RPM, como a melhor condição para maximização do rendimento e a mais adequada para processamento da polpa do camu-camu.

\section{CONCLUSÃO}

Observou-se que o procedimento de desidratação do camu-camu no tambor rotatório com recheio de inertes mostrou-se eficaz, uma vez que foram obtidos excelentes resultados nas análises, com atividades de água menores que 0,4 e umidades menores que $10 \%$. O ponto ótimo do processo deu-se nas condições do experimento 6 , ou seja, quando o agente carreador maltodextrina foi utilizado na porcentagem de $15 \%$, diminuindo a pegajosidade do material e sua aderência nas paredes do tambor rotatório, e consequentemente, aumentando o rendimento, associada as variáveis temperatura de $90^{\circ} \mathrm{C}$, fator de enchimento de $28 \%$, rotação de 65 RPM.

\section{REFERÊNCIAS BIBLIOGRÁFICAS}

ANGEL, R. M. C.; MUNOZ, L. C. E.; AVILES-AVILES, C.; GARCÍA, R.G.; SANTILLÁN, M.M.; LAGUNES, A. G.; ARCHILA, M. A. Spray-drying of passion fruit juice using lactose maltodextrina blends as the support material. Braz. Arch. Biol. Techn., CuritibaPR, v. 52, n. 4, p. 1011-1018, 2009.

AOAC, Association of Official Analytical Chemists. Official methods of analysis. Gaithersburg, MD: AOAC, 1995.

FREITAS, L. V. D. Estudo sobre a desidratação de microalgas em secador rotatório. Trabalho de conclusão de curso (Engenharia Química) - Faculdade de Engenharia Química, Universidade Federal de Uberlândia, Uberlândia-MG, 2017.

FUJITA, A.; BORGES, K.; CORREIA, R.; FRANCO, B.; GENOVESE, M. Impact of spouted bed drying on bioactive compounds, antimicrobial and antioxidant activities of commercial frozen pulp of camu-camu (Myrciaria dubia Mc. Vaugh). Food Res Int, v. 54, p. 495-500, 2013

KROKIDA, M. K.; MAROULIS, Z. B.; KREMALIS, C. Process design of rotary dryers for olive cake. Dry.Technol., v. 20, n. 4-5, p. 771-788, 2002.

LIMAVERDE JR, J. R. Secador Rotatório com Recheio de Inertes Aplicado a Secagem de Materiais Pastosos. Dissertação de Mestrado, Programa de Pós-Graduação em Engenharia Química, Universidade Federal de Uberlândia (UFU), Uberlândia-MG, 78 p., 2000.

RODRIGUES, R. B.; MENEZES, H. C.; CABRAL, L. M. C.; DORNIER, M., RIOS, G. M.; REYNES, M. Evaluation of reverse osmosis and osmotic evaporation to concentrate camu-camu juice (Myrciaria dubia). J. Food Eng., v. 63, p. 97-102, 2004. 